\title{
Variability and trends in England and Wales precipitation
}

Article

Accepted Version

de Leeuw, J., Methven, J. and Blackburn, M. (2016) Variability and trends in England and Wales precipitation. International Journal of Climatology, 36 (8). pp. 2823-2836. ISSN 08998418 doi: https://doi.org/10.1002/joc.4521 Available at https://centaur.reading.ac.uk/43687/

It is advisable to refer to the publisher's version if you intend to cite from the work. See Guidance on citing.

Published version at: http://dx.doi.org/10.1002/joc.4521

To link to this article DOI: http://dx.doi.org/10.1002/joc.4521

Publisher: John Wiley \& Sons

All outputs in CentAUR are protected by Intellectual Property Rights law, including copyright law. Copyright and IPR is retained by the creators or other copyright holders. Terms and conditions for use of this material are defined in the End User Agreement.

\section{www.reading.ac.uk/centaur}

\section{CentAUR}

Central Archive at the University of Reading

Reading's research outputs online 
UK. Email: j.deleeuw@pgr.reading.ac.uk

†j.methven@reading.ac.uk

${ }^{\ddagger}$ m. blackburn@reading.ac.uk

\title{
Variability and trends in England and Wales Precipitation
}

\author{
J. de Leeuw*1, J. Methven ${ }^{\dagger 1}$, and M. Blackburn ${ }^{\ddagger 2}$ \\ ${ }^{1}$ Department of Meteorology, University of Reading \\ ${ }^{2}$ National Centre for Atmospheric Science, University of Reading
}

September 3, 2015

\begin{abstract}
The England and Wales Precipitation (EWP) dataset is a homogeneous time series of daily accumulations from 1931 to 2014, composed from rain gauge observations spanning the region. The daily precipitation statistics are shown to be well described by a Weibull distribution, which is used to define extremes in terms of percentiles. Computed trends in annual and seasonal precipitation are sensitive to the period chosen, due to large variability on interannual and decadal timescales. Atmospheric circulation patterns associated with seasonal precipitation variability are identified. These patterns project onto known leading modes of variability, all of which involve displacements of the jet stream and storm-track over the eastern Atlantic.

The intensity of daily precipitation for each calendar season is investigated by partitioning all observations into 8 intensity categories contributing equally to the total precipitation in the dataset. Contrary to previous results based on shorter periods, no significant trends of the most intense categories are found between 1961-2014, except for a small negative trend in the most extreme category of summer precipitation. The area-average precipitation is found to share statistical properties common to the majority of individual stations across England and Wales used in previous studies.

Statistics of the EWP data are examined for multi-day accumulations up to 10 days, which are more relevant for river flooding. Four recent years (2000, 2007, 2008 and 2012) have a greater number of extreme events than any previous year in the record. It is the duration of
\end{abstract}


precipitation events in these years that is remarkable, rather than the magnitude of the daily accumulations.

Keywords: atmospheric circulation variability, precipitation statistics, extremes

\section{Introduction}

The United Kingdom is situated at the downstream end of the North Atlantic storm-track and is characterised by strong variations in precipitation. This variability of precipitation on monthly, seasonal and interannual timescales has a major impact on society through, for example, crop production [Porter and Semenov, 2005] and water supply [Wilby et al., 2006].

Local precipitation totals are influenced by many factors and, as a result, individual rain gauge accumulations can vary substantially on a day to day basis, even when separated by only several kilometers. Therefore, to study mean precipitation changes and variability over a country, a dense rain gauge network is needed to estimate the area average precipitation. There is a long history of precipitation measurements in the UK, with a dense rain gauge network measuring precipitation for many years. The longest rain gauge records date back to the eighteenth century, making them one of the longest precipitation observation records in the world [Woodley, 1996, Rodda et al., 2009].

The availability of high resolution observations in the UK has resulted in a large number of studies investigating the occurrence of variability and trends in precipitation on various timescales [Hand et al., 2004, Burt and Ferranti, 2012, Jones et al., 2014]. Despite using different analysis methods and rain gauge configurations, most studies conclude that the annual precipitation totals are approximately unchanged since the 1960s [Thompson, 1999, Fowler and Kilsby, 2003, Biggs and Atkinson, 2011].

In contrast, large variations have been observed in seasonal precipitation totals. Wigley et al. [1984b] and Wigley and Jones [1987] (later updated by Jones and Conway [1997]) investigated the area-average seasonal precipitation series for England and Wales between 1767 and 1995 and concluded that winter (DJF) precipitation increased significantly over that period (a linear trend gives an increase of $67 \mathrm{~mm}$ between $1767-1995$, which is $28 \%$ of the climatological average). In contrast, precipitation decreased in summer (JJA) as a linear trend between 1767-1995 gives a decrease of $41 \mathrm{~mm}$, which is $17 \%$ of the climatological average. Jones and Conway [1997] only 
found the winter trend to be significant at the $95 \%$ level and even here an apparent step change in the 1860s suggested issues with data inhomogeneity in the earlier period. Shorter period trends were found to be of questionable significance due to large interannual variability. As a result, spring and autumn have not shown any significant long term trends. Similar results have been found when including more recent observations (e.g. Alexander and Jones [2000], Osborn and Hulme [2002], Mills [2005]).

A number of studies have linked variability and trends in UK seasonal precipitation over recent decades to changes in the large scale atmospheric circulation, including the North Atlantic storm-track. Increasing winter precipitation between the 1960s and 1990s has been linked to a trend towards more westerly flow and increased storm frequency, characterised as a trend from negative to positive phase of the North Atlantic Oscillation (NAO) [Jones and Conway, 1997, Osborn and Hulme, 2002]. However, since the 1990s this trend in the NAO has reversed [Hartmann et al., 2013]. More recently Sutton and Dong [2012] and Dong et al. [2013] have linked changes on decadal timescales in summer precipitation over north-west Europe, including the UK, to variability in Atlantic sea surface temperatures, represented by the Atlantic Multi-decadal Oscillation (AMO) [Sutton and Hodson, 2005], and associated changes in the summer NAO atmospheric circulation. Several studies have sought to identify seasonal precipitation variability with large-scale atmospheric flow patterns by computing pointwise regressions of precipitation with indices of known modes of variability. Wibig [1999] used this method to obtain patterns of monthly precipitation variability associated with the leading modes of Atlantic and European circulation variability, including the NAO and the East Atlantic (EA) pattern (previously identified by Barnston and Livezey [1987]). Bladé et al. [2012] obtained precipitation and surface air temperature anomalies associated with the winter and summer NAO. In winter, positive NAO is associated with positive precipitation anomalies over northern Europe, including Scotland and Northern Ireland, and negative anomalies over southern Europe. In summer the correlations are reversed and displaced equatorward, with a negative correlation between NAO and precipitation over the entire UK. This seasonal reversal is related to differing locations of the NAO geopotential height and surface pressure anomalies in winter and summer, which in turn are related to jet stream latitude and the preferred paths of Atlantic storms [Woollings et al., 2010].

In recent years there has been an additional focus on the characteristics of daily and 
multi-day precipitation and their extremes, which are particularly relevant to flooding. A number of studies sought evidence for increases in the intensity of UK daily precipitation and the frequency of extremes [Osborn et al., 2000, Osborn and Hulme, 2002, Maraun et al., 2008, Jones et al., 2013, 2014], consistent with hypothesised changes in the global hydrological cycle for a warming climate [Trenberth et al., 2003].

Using data from over 100 rain gauges in the UK, Osborn et al. [2000] found that the main contributor to increases in seasonal precipitation in winter for the period 1961-1995 was wet day amount, a measure of precipitation intensity. Trends in wet day probability were more spatially variable, but contributed to increased winter precipitation in the west of the UK. In contrast, decreasing seasonal precipitation in summer was found to be associated mainly with a decrease in wet day probability.

By partitioning daily precipitation into 10 intensity categories, Osborn et al. [2000] showed that the trends in precipitation intensity were characterised by a decreasing relative contribution of light precipitation and an increasing contribution of heavy precipitation in winter, with an opposite shift towards days with lighter precipitation in summer. Using the same methodology, Osborn and Hulme [2002] and Maraun et al. [2008] extended the analysis period to 2000 and 2006 respectively. These studies found a weaker trend in intensity in winter for the extended periods and a reversal of the previous summer trend to 2006, with evidence that the summer trend was more likely associated with interdecadal variability, being strongly influenced by several extreme events in the 1960s [Maraun et al., 2008], and that observations over the last two decades had shown increased inter-annual variability [Wood, 2004]. Using sparser observations over a longer period for the UK, Maraun et al. [2008] also presented evidence of increased daily precipitation intensity in spring and autumn.

The impact of flooding associated a number of the extreme wet seasons in recent years in the UK (autumn 2000, summer 2007, summer/autumn 2012, winter 2013/14) motivates a reexamination of the entire EWP timeseries and previous conclusions regarding variability. This paper investigates and updates timeseries of observed annual, seasonal and daily precipitation accumulations across England and Wales using an area-average precipitation dataset (EWP, described in section 2.). The focus is to characterise the observed precipitation variability and the nature of multi-decadal variations and to link this with the variability in the circulation patterns. 
In addition, multi-day accumulations are also investigated for possible changes in precipitation intensity. Based on decadal return period estimates of 1,2, 5 and 10 day precipitation accumulations, both Jones et al. [2013] and Jones et al. [2014] found a small increase in the strength of 5-day and 10-day precipitation accumulation events across various subregions in the UK between 1961-2010 and indicated their potential impact on e.g. flood risk management.

Section 2 describes the EWP dataset and the methodology used to investigate precipitation variability. The results for annual and seasonal precipitation observations are discussed in section 3 , together with the large scale atmospheric circulation patterns associated with variations and extremes in seasonal precipitation. The daily precipitation is investigated in section 4 . In section 5 multi-day precipitation and its implications are presented. Finally section 6 summarises and discusses the findings.

\section{Observations: England and Wales Precipitation}

The England and Wales Precipitation (EWP) data used in this study are a spatial average of individual rain gauge observations over the England and Wales region [Alexander and Jones, 2000]. The daily data are maintained and updated by the Met Office Hadley Centre and are available from 1931 to the present day (www.metoffice.gov.uk/hadobs/hadukp/). They have been used as a standard precipitation measure by many studies (e.g. Jones and Conway [1997] and Mills [2005]), as they constitute one of the longest homogeneous daily precipitation datasets available.

The England and Wales precipitation estimates are based on the weighted contribution of 5 climatologically different sub-regions defined by Wigley et al. [1984b]. In each sub-region, 7-15 evenly distributed stations (depending on the availability of data [Alexander and Jones, 2000]) are included to determine the precipitation accumulation for the region. Each station is scaled by its corresponding regional monthly climatological average, so that the regional data are not weighted towards sites with locally high precipitation (e.g. due to local orographic effects). This scaling also allows varying gauge configurations (due to changing networks) to be combined to produce a robust and homogeneous time series. The England and Wales Precipitation series (EWP) is a weighted average of the five regions, where the weights are determined by regression analysis. More information on the definition of the five regions, the averaging and the regression analyses can be found in Wigley et al. [1984a], Wigley et al. [1984b], Wigley and Jones [1987] and Alexander and 
Jones [2000].

When describing extreme precipitation events, recent work by Jones et al. [2014] suggests that the 5 sub-regions defined by Wigley et al. [1984b] across the England and Wales region are not sufficient to capture the sub-regional changes. Instead, 9 different sub-regions were defined that are thought better able to capture trends and variability in sub-regional extreme precipitation. However, Jones et al. [2014] did not discuss the combined impact of these new 9 sub-regions on the England and Wales area average extremes, but only investigated the precipitation signals in the individual sub-regions. As no EWP equivalent dataset is available based on the 9 sub-regions, the impact on the area average precipitation cannot be assessed directly.

However, studies by Croxton et al. [2006] and Simpson and Jones [2012] showed that higher density datasets for the England and Wales region only resulted in marginal improvement of the areal precipitation estimate. Simpson and Jones [2012] compared the EWP observations with a newly developed 5-km gridded daily precipitation set by the Met Office Hadley Centre. They found that for $98 \%$ of all daily observations, both datasets agreed within $1 \mathrm{~mm}$ and $90 \%$ agreed within $0.5 \mathrm{~mm}$. Croxton et al. [2006] used the EWP data to show that monthly precipitation timeseries of individual stations are strongly correlated with the area average precipitation amount over the England and Wales region. This gives confidence that the EWP dataset is a robust estimate of precipitation for the entire region and that the EWP data may be used to investigate trends and variability in precipitation over England and Wales.

Daily EWP observations will be separated between 'precipitation' days and 'dry' days, to investigate variability and trends in precipitation intensity, with days having less than $0.1 \mathrm{~mm}$ of area-averaged precipitation defined to be dry. In previous studies the definition of a 'dry' day at individual gauge stations varies between $0.1-0.3 \mathrm{~mm} /$ day, related to the precision of gauge measurements. As the EWP data are an area average, the lower threshold is selected here. Using a higher threshold ( 0.2 or $0.3 \mathrm{~mm} /$ day) has only a small impact on the results presented. 


\section{Seasonal precipitation variability and its relation to large- scale circulation}

Using daily EWP observations from 1931-2014, a timeseries of annual precipitation accumulations was constructed and is shown in figure 1. The long-term mean annual precipitation for this period and corresponding interannual standard deviation can be found in table 1. There is significant interannual variability, with a standard deviation of $115.1 \mathrm{~mm}$ (equivalent to $0.315 \mathrm{~mm} /$ day), which results in a coefficient of variation $(\mathrm{CV}$, defined as the ratio of the standard deviation to the mean) of 0.12. Using a linear least squares fit, the annual precipitation dataset was tested for robust trends between 1931 and 2014 using the standard Mann-Kendall test. In agreement with previous studies, no significant trend in annual precipitation was found (the slope of the best fit is $0.85 \pm 1.02 \mathrm{~mm} /$ year$)$.

In contrast to annual precipitation, previous studies have found significant trends in seasonal precipitation accumulations over the UK [Alexander and Jones, 2000, Mills, 2005]. The EWP observations for individual seasons (table 1) show a seasonal dependence of the precipitation accumulations, with a maximum in autumn ( $\mathrm{SON})$ and a minimum in spring (MAM). The data also show large interannual variability. The standard deviations shown in table 1 result in a CV between 0.26 and 0.29 for all four seasons. Note that DJF is labeled by the year containing January. As a result, the DJF seasonal analyses are for the period 1932-2014, rather than 1931-2014 used for the other three seasons.

In addition to large interannual variability in seasonal EWP, figure 2 also reveals the presence of decadal and multi-decadal variability, including clusters of wet and dry seasons. To investigate whether this is true for all four seasonal averages, linear trends were determined for the entire 84 year period and for three additional periods (1961-2006, 1961-2014 and 1979-2014), using linear least squares fits. For the 1931-2014 period, no significant trend is found in any of the seasons (see table 1 ).

The period between 1961-2006 used in previous studies (e.g. Maraun et al. [2008]) gives a positive trend in winter and a negative trend in summer for the EWP observations, although neither trend is significant at the $95 \%$ level (see table 1 and figure 2). For DJF, MAM and SON the linear trends are slightly modified by including the data between 2007 and 2014. However, more 
interestingly, including the most recent observations for JJA changes the slope from negative to positive. For JJA the period 2007-2012 was consistently wet, with all 6 years above the long term average including the most extreme wet summers (2007 and 2012) recorded since 1931. Although the JJA trend for the period 1961-2014 is not significant (using the standard MannKendall significance test) for the EWP dataset, it clearly illustrates the danger of computing trends following extremes, where extremes at the end (or beginning) of series more strongly influences the trend. Figure 2 shows that the linear trends in seasonal precipitation observations are strongly influenced by the large variability. Therefore they should not be interpreted as climatic trends in precipitation over the England and Wales region.

As discussed in the introduction, several previous studies have used regression analysis to identify precipitation patterns associated with the principal component time series for patterns of atmospheric variability obtained by analyses of covariance in geopotential height. Here, atmospheric circulation patterns associated with EWP variability are sought using pointwise regressions of dynamical variables with the timeseries of seasonal EWP. This identifies the large-scale flow anomalies specifically related to precipitation variability over England and Wales.

Figure 3 shows the pointwise correlation of seasonal average $500 \mathrm{hPa}$ geopotential height with seasonal average EWP observations. This calculation uses the NCEP-NCAR reanalysis over the period 1961-2013 for each of the four calendar seasons over the Northern Hemisphere extratropics. The common feature at all times of year is a strong negative correlation centered close to the British Isles, representing the centre of a mid-tropospheric trough in the wetter seasons. This feature corresponds to an equatorward displacement and extension of the seasonal jet stream near the UK, since the climatological jet latitude is close to $55^{\circ} \mathrm{N}$ over the eastern Atlantic in all seasons. A similar feature to that in $500 \mathrm{hPa}$ height appears in correlations with mean sealevel pressure (not shown), consistent with the contribution of extra-tropical cyclones to England and Wales precipitation in all seasons [Hawcroft et al., 2012]. The reversed pattern in dry seasons corresponds to a ridge over the British Isles and poleward displacement of the jet stream and stormtrack. Further from the British Isles, large differences are evident between the seasonal 500hPa height correlation patterns. In winter the pattern over the Atlantic basin more closely resembles the East Atlantic (EA) pattern identified by Barnston and Livezey [1987] than the North Atlantic Oscillation (NAO). These two patterns of variability form a quadrature pair in latitude in winter, 
and it is the EA pattern whose main node of geopotential height variability is at the latitude of the UK. The summer correlation pattern more closely resembles the negative phase of the summer NAO, which has its negative height centre near $55^{\circ} \mathrm{N}$ and its positive centre over Greenland in that season. Note also the trough present further upstream over eastern North America, which is related to a stationary Rossby wave pattern as discussed for summer 2007 by Blackburn et al. [2008]. In spring and autumn the height correlation patterns are more suggestive of wavetrains propagating from the sub-tropical Atlantic. For autumn, the negative centre close to the UK and positive centre over Scandinavia project strongly onto the Scandinavian pattern of variability, identified as a leading mode of variability in autumn by Barnston and Livezey [1987]. This pattern of height anomalies was a feature of the extreme wet Autumn over England and Wales in 2000 [Hoskins, 2003].

In order to test the linearity of the seasonal correlations, figure 4 shows $500 \mathrm{hPa}$ geopotential height composites for the five wettest and driest seasons in EWP over the period 1961-2013, for winter and summer only. Note that the pattern observed for the 5 wettest summers in figure $4 \mathrm{~b}$ is very similar to that found for the summers 2007-2012 (not shown): two of the five wettest seasons (2007 and 2012) are part of the composite shown here. The difference between the wet and dry composites is predominantly a sign reversal of the anomalies, and the patterns closely resemble the correlation maps shown in figure 3. However, the dry composites more closely resemble an isolated high/ridge over the UK surrounded more symmetrically by low heights, indicative of blocking episodes, whereas the wet composites have larger zonal scale or (in spring and autumn, not shown) more closely resemble wavetrains with specific orientation.

\section{Daily precipitation and extremes}

The observed variability shown in the seasonal precipitation can be related to a change in the 'wet' day probability and/or an increase in precipitation intensity on 'wet' days. To investigate possible changes in the area average precipitation intensity over England and Wales, it is necessary to define a threshold for extremes based on the statistical distribution of daily EWP. Figure 5 shows the probability density function (PDF) for the daily precipitation between 1931-2014, including only the 'precipitation' days for all calendar months, where a 'precipitation' day is defined having more than $0.1 \mathrm{~mm}$ of precipitation. The figure uses a logarithmic frequency scale, to focus on the wet 
extremes. Following Mills [2005], the observations are fitted using a Weibull distribution (not valid for $x<0)$

$$
f(x)=\frac{k}{\lambda}\left(\frac{x}{\lambda}\right)^{k-1} \exp \left[-\left(\frac{x}{\lambda}\right)^{k}\right] \quad \text { for } x \geq 0,
$$

where $\lambda$ is the scale parameter and $k$ the shape parameter. The best representation of the daily observations is given by the Weibull distribution with scale and shape parameters of $\lambda=2.30 \pm 0.06$ and $k=0.72 \pm 0.02$ respectively, as indicated by the solid line in figure 5 .

The close fit of daily precipitation by the Weibull distribution allows a threshold for extremes to be determined that is independent of the limited number of extreme events in the observations. Here the upper $2 \%$ of the total distribution is defined as extreme, which corresponds to approximately 4 events per year. The resulting threshold using data for all calendar months $(13.8 \mathrm{~mm} /$ day $)$ is depicted by the dashed line in figure 5 .

Previous studies [Thompson, 1999, Alexander and Jones, 2000, Jones et al., 2013] have found large variations in daily extremes between the seasons, hence table 2 also shows the $2 \%$ extreme threshold for each season. Although the daily EWP distributions for individual seasons are more noisy, the shapes of the seasonal distributions are similar and the seasonal Weibull shape parameters do not vary significantly from their annual values. The scale parameter, representing the overall magnitude of the distribution, is strongly coupled to differences in the seasonal precipitation accumulations presented in table 1 . As a result, the $2 \%$ threshold criterion does have a strong seasonal dependence, with a maximum of $15.8 \mathrm{~mm} /$ day in autumn and a minimum of 12.0 $\mathrm{mm} /$ day in spring. Seasonal thresholds are therefore used throughout this paper to define extreme events for daily and multi-day accumulations.

Recent studies of daily intensity extremes have mostly found a positive trend in extreme winter precipitation, related to increased cyclonic activity over the region [Maraun et al., 2011, Rodda et al., 2010, Jones et al., 2013]. In summer a negative trend in extreme precipitation has been observed between 1961 and 1995 [Osborn et al., 2000], but recent studies indicate that intense summer precipitation trends might have reversed since 2000 [Maraun et al., 2008, Jones et al., 2014], suggesting that changes in summer precipitation intensity are related to variability on seasonal to decadal timescales rather than being indicative of long-term trends.

Trends in daily extreme precipitation for the calendar seasons are investigated in the EWP data using the methodology introduced by Osborn et al. [2000] and also used by Osborn and Hulme 
[2002] and Maraun et al. [2008] to investigate seasonal extreme precipitation and its trends over the UK using a dense network of gauges (individual time series). In these studies, for each calendar season and individual gauge, all 'precipitation day' observations ( $>0.1 \mathrm{~mm} /$ day) between 19611995 were sorted by intensity, and sub-divided into 10 precipitation categories. The categories were defined such that each category accounts for $10 \%$ of the total precipitation accumulation between 1961-1995 (i.e. category 1 contains all the light precipitation events that together contribute to $10 \%$ of the total accumulation between 1961-1995). Using this 'accumulation criterion' rather than an 'event based criterion' (by which each category would contain $10 \%$ of all precipitation days) results in fewer events in each of the high intensity categories, giving more detailed information on extreme precipitation.

In the original method developed by Osborn et al. [2000], the precipitation spectrum was divided into 10 categories (each category containing $10 \%$ of the total precipitation over the reference period 1961-1995). The EWP dataset used in this study is an aggregate of multiple rain gauge stations, resulting in a precipitation timeseries that is smoother and contains smaller extreme values compared to the individual gauge observations used by Maraun et al. [2008]. To reduce the sampling error due to a small number of extreme events in the most extreme category, only 8 categories are used here, each representing $12.5 \%$ of the total precipitation.

Using standard linear regression, each of the EWP categories for each calendar season is investigated for trends. The results are shown in figures 6 and 7 , where coloured bars indicate trends that are significant at the $90 \%$ level using a standard Mann-Kendall test. To compare the area average EWP observations and the individual gauge data used by Maraun et al. [2008], trends for all categories are first investigated for the same years used in their study (1961-2006) and shown in figure 6 . Results are shown for the four seasons separately.

For winter (DJF) no significant trends are present in any of the precipitation categories. Therefore we cannot reject the null-hypothesis that the seasonal precipitation timeseries are stationary. However, the variation of trend with precipitation category agrees with the results of Maraun et al. [2008], who found a decrease in the lighter precipitation categories and an increase in the most extreme precipitation categories. Figure $6 \mathrm{c}$ shows that the opposite trends are observed in EWP in summer, with a significant decrease in the most extreme precipitation category between 1961-2006. This is also in agreement with the results of Maraun et al. [2008]. The area average 
EWP observations therefore contain the same qualitative changes in precipitation intensity that are present in individual station data.

When the timeseries are extended to 2014, shown in figure 7, the category trends are in general qualitatively similar but weakened, indicating that the previous trends in precipitation intensity have not been sustained. This is consistent with a recent study of 223 individual rain gauge records by Jones et al. [2013], which found that wet summers have been more frequent in the last decade.

Only summer shows a trend towards decreasing precipitation intensity which is significant at the $90 \%$ level in both periods. However, when the period is extended further backwards in time to 1931, shown in figure 8, no significant trends remain for any of the seasons. There is therefore no robust evidence to distinguish long-term linear trends from variability in EWP for any season, either for total seasonal precipitation or for daily precipitation intensity.

\section{Multi-day accumulations and extremes}

When considering the impact of precipitation on flooding, it is important to also consider multi-day precipitation accumulations [Jones et al., 2013, 2014]. Figure 9 shows PDFs and corresponding cumulative distribution functions (CDFs) of running 1, 3, 5 and 10 day accumulations of daily EWP. Overlapping multi-day periods are counted as separate events. Using these distributions, the extreme events are defined as those exceeding the upper $2 \%$ of multi-day accumulated precipitation (see table 2), as previously used for the 1-day accumulations. The $2 \%$ precipitation threshold is obtained using the empirical CDF and is determined separately for each season to account for the seasonal differences in mean precipitation (table 1 and figure 2). The resulting threshold values for extreme events in each season and for each accumulation period can be found in table 2 .

Based on the upper $2 \%$ threshold value for precipitation in each calendar season, the number of extreme events is determined for each calendar year. Figure 10 shows the total number of extreme events for the 4 accumulation intervals discussed earlier. Note that the total number of events in the 1-day observations differs from the multi-day accumulations. This is related to the fact that individual 'dry' days $(<0.1 \mathrm{~mm})$ are excluded from the 1-day observations but are included in the multi-day precipitation accumulations, which only exclude multi-day 'dry' periods with $<0.1 \mathrm{~mm}$ over the accumulation period. As a result, the average number of extreme events 
in the 1-day accumulations is smaller and should not be compared with the number of events in the other panels.

Figure 10 reveals that there is strong interannual variability for each of the precipitation accumulation periods. There is a small upward trend in the daily accumulations toward more extreme events (a least squares linear fit gives an increase of 0.3 days/decade), although high numbers of extreme events were also observed in the early 1980s and 2000s. This result is in agreement with figure 7, where the combined effect of the highest category (sum of the righthand bars for all four seasons) gives a similar small upward trend in the extreme precipitation accumulations. However, as a result of the large variability, the trend is not significant at the $90 \%$ level.

For longer accumulation periods, it is apparent from figure 10 that more extreme events have been observed in the last decade. It is also clear that 2012 has the highest number of extreme 1, 5 and 10-day precipitation accumulation events since the start of the daily EWP observation period and it is the second most extreme year for the running 3-day accumulation.

Furthermore, for the 3,5 and 10 day accumulations, the most extreme years occur from 2000 onward. For 2000, 2007, 2008 and 2012 the number of extreme periods in the 3 and 5 day accumulations is much larger than in the period prior to 2000.

The extreme events contributing to the most exceptional annual counts took place in different seasons (autumn 2000, summer 2007, spring 2008 and summer/autumn 2012), so no individual season is responsible. Comparing all four timeseries in figure 10 indicates that, although the number of daily extremes has been above average, it is the duration of extreme events since 2000 that has been exceptional.

\section{Conclusions and Discussion}

Using the England and Wales Precipitation (EWP) data, which are an area average precipitation estimate for England and Wales, the variability in annual, seasonal and daily precipitation totals has been investigated for the period 1931-2014. In agreement with previous studies (e.g. Fowler and Kilsby [2003] and Biggs and Atkinson [2011]), no robust linear trends in annual precipitation totals can be distinguished from the interannual variability (the coefficient of variation has a value of 0.12 ). The EWP seasonal precipitation is characterised by a larger variability on interannual to decadal timescales (coefficient of variation between 0.26 and 0.30 ), which previous studies have 
related to changes in the large-scale circulation and the sea surface temperature anomalies over the North Atlantic region (e.g. Sutton and Dong [2012] and Dong et al. [2013] for summer).

Previous studies investigating precipitation variability in the UK have been mostly based on either individual rain gauge timeseries [Osborn et al., 2000, Maraun et al., 2008] or averages over smaller subregions of England and Wales [Jones et al., 2013, 2014]. In this study the country-wide EWP dataset is found to give similar results, which indicates coherent behaviour on the scale of England and Wales and the synoptic scale nature of the precipitation variability.

Spatial maps of pointwise correlation of seasonal average 500hPa geopotential height with seasonal average EWP show for all seasons a strong negative correlation centered close to the British Isles. This is consistent with the large contribution of extra-tropical cyclones to England and Wales precipitation in all seasons [Hawcroft et al., 2012]. In winter, the 500hPa geopotential height correlation pattern over the Atlantic basin more closely resembles the East Atlantic (EA) pattern than the North Atlantic Oscillation (NAO), while the summer correlation pattern closely resembles the negative phase of the summer NAO. In spring and autumn the height correlation patterns are more suggestive of wavetrains propagating from the sub-tropical Atlantic. Differences between composites for the five wettest and driest seasons in EWP over the period 1961-2013 show predominantly a sign reversal of the anomalies, indicating approximate linearity of the seasonal correlations. For all wet seasons, the common factor is an equatorward shift and eastward extension of the North-Atlantic jet and the associated storm-track over the eastern Atlantic.

Due to the large variability in seasonal precipitation, computed long term trends are sensitive to the period chosen. For the 1931-2014 period, no significant trend has been found for the seasonal precipitation timeseries. DJF precipitation increased from the 1960 s to a maximum in the early 1990s, but has decreased since then, removing the significant upward trend reported previously by others [Jones and Conway, 1997, Osborn et al., 2000]. Previous reported negative trends for the summer season [Osborn and Hulme, 2002] have been reversed since 2007, as all summers between 2007 and 2012 were anomalously wet, with 2007 and 2012 being the two wettest summers on record in the EWP dataset.

Following the method developed by Osborn et al. [2000] for individual rain gauges within England and Wales, the daily precipitation has been divided into 8 intensity categories (separately or each season), contributing equal weight to the total precipitation. The EWP data between 1961- 
2014 show no significant long term trends in autumn, winter or spring for any extreme categories. The only significant trend present is the downward trend for most extreme events for JJA. For the shorter period (1961-2006) used by Maraun et al. [2008], the EWP dataset generally show similar results to those at individual rain gauge stations. However this period shows a stronger negative trend in the most extreme events for JJA and a non-significant trend in the most extreme category in DJF. These trends are not robust for the 1931-2014 window. Contrary to the study by Maraun et al. [2008], EWP shows a significant increase of the most extreme events in autumn.

The probability distribution of daily EWP observations is best described by a Weibull distribution. This gives a close fit to the observations for both light and extreme events, giving confidence that it can be used to represent the entire range of area average precipitation. An extreme precipitation threshold has been determined using the Weibull distribution for all daily data since 1931 (no separation between seasons), with the upper 2\% of 'precipitation days' (days with more than $0.1 \mathrm{~mm}$ ) being selected to represent extreme events. The $2 \%$ extreme threshold shows a strong seasonal dependence, consistent with differences between the seasonal average accumulations (Table 2).

Finally the frequency of multi-day precipitation accumulations has been investigated, using the same $2 \%$ extreme threshold for multi-day accumulations as used for daily data. The 3,5 and 10 day accumulations show that the period 2000-2014 contained more extreme multi-day accumulations than the average between 1931-2014, while the daily precipitation did not. The 5 and 10 day accumulations in particular contain 4 very distinct years $(2000,2007,2008,2012)$, in which the number of extremes is 5 times higher than the long term average. The extreme precipitation periods occurred in different seasons for each of these years (autumn 2000, summer 2007, spring 2008, summer/autumn 2012), suggesting a similar behaviour throughout the year with more extremes on the multi-day accumulation scale in the recent years.

The recent cluster of extreme multi-day accumulations merits further investigation. Figure 4 indicates that it has been accompanied by persistence of an upper level trough over the east Atlantic and the British Isles, as discussed for summer 2007 by Blackburn et al. [2008]. Many studies have shown impact of large scale circulation variability on European climate. Saeed et al. [2014] showed that the upper level circulation has a large influence on the European summer precipitation variability. While the circulation patterns related to internal variability are known, 
the reason for their increased occurrence in recent years is unknown. It is therefore important to investigate the dynamical processes associated with this behaviour and whether they can be ascribed to anomalous forcing or change in global circulation.

The results indicate that in future climate, changes in circulation could exert a strong influence on precipitation variability. However it is uncertain whether current climate models are able to capture the circulation variability. For example Pearson et al. [2014] have shown that, although the high-resolution climate model HIGEM can simulate the accumulated precipitation in a case study (such as the Tewkesbury storm in July 2007), the statistics of precipitation in a historic twentieth century simulation differ markedly from the observed EWP characteristics. While the PDF of daily accumulations over England and Wales from a simulation with prescribed SSTs matches closely the PDF derived from the EWP data (as shown in figure 9), the model underestimates the occurrence of large accumulations on 3, 5 and 10-day timescales. This indicates that the model does not represent persistence in circulation patterns associated with the most extreme rainfall events. The reasons for this deficiency in climate model performance are not known, but the spatial resolution may be an important factor. For example, Dawson et al. [2012] have shown using the ECMWF forecast model that the 4 dominant patterns of North Atlantic atmospheric variability seen in analyses only emerge in free-running simulations when the resolution is increased to T1279 (approximately equivalent to a $16 \mathrm{~km}$ grid spacing) as used in current high resolution deterministic forecasts.

\section{Acknowledgements}

We would like to acknowledge the Met Office for providing the HadUKP observations datasets at www.metoffice.gov.uk/hadobs. The NCEP-NCAR Reanalyses figures were obtained using the website http://www.esrl.noaa.gov/psd/ (NOAA/ESRL Physical Sciences Division, Boulder Colorado). We also thank the reviewers for their valuable comments, which improved this paper. Furthermore the first author would like to thank the school of Mathematical and Physical Sciences and the University of Reading for funding his PhD studentship and NCAS-Climate for subsequent support. 


\section{References}

L. V. Alexander and P. D. Jones. Updated Precipitation Series for the UK and Discussion of Recent Extremes. Atmos. Sci. Lett., 1(2):142-150, 2000. doi: 10.1006/asle.2000.0016.

A. G. Barnston and R. E. Livezey. Classification, Seasonality and Persistence of Low-Frequency Atmospheric Circulation Patterns. Mon. Weather Rev., 115:1083-1126, 1987. doi: 10.1175/ 1520-0493(1987)115\%3C1083:CSAPOL\%3E2.0.CO;2.

E. M. Biggs and P. M. Atkinson. A characterisation of climate variability and trends in hydrological extremes in the Severn Uplands. Int. J. Climatol., 31(11):1634-1652, 2011. doi: 10.1002/joc. 2176.

M. Blackburn, J. Methven, and N. Roberts. Large-scale context for the UK floods in summer 2007. Weather, 63(9):280-288, 2008. doi: 10.1002/wea.322.

I. Bladé, B. Liebmann, D. Fortuny, and G.J. van Oldenborgh. Observed and simulated impacts of the summer NAO in Europe: implications for projected drying in the Mediterranean region. Clim. Dyn., 39(3-4):709-727, 2012. doi: 10.1007/s00382-011-1195-х.

T. P. Burt and E. J. S. Ferranti. Changing patterns of heavy rainfall in upland areas: a case study from northern England. Int. J. Climatol., 32(4):518-532, 2012. doi: 10.1002/joc.2287.

P. J. Croxton, K. Huber, N. Collinson, and T. H. Sparks. How well do the Central England Temperature and the England and Wales Precipitation Series represent the climate of the UK? Int. J. Climatol., 26(15):2287-2292, 2006. doi: 10.1002/joc.1378.

A. Dawson, T. N. Palmer, and S. Corti. Simulating regime structures in weather and climate prediction models. Geophys. Res. Lett., 39(21), 2012. doi: 10.1029/2012GL053284.

B. Dong, R. T. Sutton, T. Woollings, and K. Hodges. Variability of the North Atlantic summer storm track: mechanisms and impacts on European climate. Environ. Res. Lett., 8(3), 2013. doi: $10.1088 / 1748-9326 / 8 / 3 / 034037$.

H. J. Fowler and C. G. Kilsby. A regional frequency analysis of United Kingdom extreme rainfall from 1961 to 2000. Int. J. Climatol., 23(11):1313-1334, 2003. doi: 10.1002/joc.943. 
W. H. Hand, N. I. Fox, and C. G. Collier. A study of twentieth-century extreme rainfall events in the United Kingdom with implications for forecasting. Meteorol. Appl., 11(1):15-31, 2004. doi: $10.1017 / \mathrm{S} 1350482703001117$.

D. L. Hartmann, A. M. G. Klein Tank, M. Rusticucci, L. V. Alexander, S. Brönnimann, Y. Charabi, F. J. Dentener, E. J. Dlugokencky, D. R. Easterling, A. Kaplan, B. J. Soden, P. W. Thorne, M. Wild, and P. M. Zhai. Climate Change 2013: The Physical Science Basis. Contribution of Working Group I to the Fifth Assessment Report of the Intergovernmental Panel on Climate Change. Chapter 2: Observations: Atmosphere and Surface. Cambridge University Press, Cambridge, UK and New York, NY, USA, 1st edition, 2013.

M. K. Hawcroft, L. C. Shaffrey, K. I. Hodges, and H. F. Dacre. How much Northern Hemisphere precipitation is associated with extratropical cyclones? Geophys. Res. Lett., 39(24), 2012. doi: 10.1029/2012GL053866.

B. J. Hoskins. Atmospheric processes and observations. Philos. T. Roy. Soc. A: Mathematical, Physical and Engineering Sciences, 361(1810):1945-1960, 2003. doi: 10.1098/rsta.2003.1264.

M. R. Jones, H. J. Fowler, C. G. Kilsby, and S. Blenkinsop. An assessment of changes in seasonal and annual extreme rainfall in the UK between 1961 and 2009. Int. J. Climatol., 33(5):1178-1194, 2013. doi: $10.1002 /$ joc. 3503 .

M. R. Jones, S. Blenkinsop, H. J. Fowler, and C. G. Kilsby. Objective classification of extreme rainfall regions for the UK and updated estimates of trends in regional extreme rainfall. Int. J. Climatol., 34(3):751-765, 2014. doi: 10.1002/joc.3720.

P. D. Jones and D Conway. Precipitation in the British Isles: An analysis of area-average data updated to 1995. Int. J. Climatol., 17(4):427-438, 1997. doi: 10.1002/(SICI)1097-0088(19970330) 17:4〈427::AID-JOC139〉3.0.CO;2-Q.

D. Maraun, T. J. Osborn, and H. W. Rust. The influence of synoptic airflow on UK daily precipitation extremes. Part I: Observed spatio-temporal relationships. Climate Dyn., 36(1-2):261-275, 2011. doi: 10.1007/s00382-009-0710-9.

D. Maraun, T. J. Osborn, and N. P. Gillett. United Kingdom daily precipitation intensity: im- 
proved early data, error estimates and an update from 2000 to 2006. Int. J. Climatol., 28(6): 833-842, 2008. doi: 10.1002/joc.1672.

T.C. Mills. Modelling precipitation trends in England and Wales. Meteorol. Appl., 12(2):169-176, 2005. doi: $10.1017 / \mathrm{S} 1350482705001611$.

T. J. Osborn and M. Hulme. Evidence for trends in heavy rainfall events over the UK. Philos. T. Roy. Soc. A, 360(1796):1313, 2002. doi: 10.1098/rsta.2002.1002.

T J Osborn, M Hulme, P D Jones, and T A Basnett. Observed trends in the daily intensity of United Kingdom precipitation. Int. J. Climatol., 20(4):347-364, 2000. doi: 10.1002/(SICI) 1097-0088(20000330)20:43.0.CO;2-C.

K. J. Pearson, L. C. Shaffrey, J. Methven, and K. I. Hodges. Can a climate model reproduce extreme regional precipitation events over England and Wales? Q. J. R. Meteorol. Soc., 2014. doi: $10.1002 /$ qj.2428.

J. R. Porter and M. A. Semenov. Crop responses to climatic variation. Philos. T. Roy. Soc. B, 360(1463):2021-2035, 2005. doi: 10.1098/rstb.2005.1752.

H. J. E. Rodda, M. A. Little, R. G. Wood, N. MacDougall, and P. E. McSharry. A digital archive of extreme rainfalls in the British Isles from 1866 to 1968 based on British Rainfall. Weather, 64(3):71-75, 2009. doi: 10.1002/wea.354.

J. C. Rodda, M. A. Little, H. J. E. Rodda, and P. E. McSharry. A comparative study of the magnitude, frequency and distribution of intense rainfall in the United Kingdom. Int. J. Climatol., 30(12):1776-1783, 2010. doi: 10.1002/joc.2024.

S. Saeed, N. Van Lipzig, W.A. Müller, F. Saeed, and D. Zanchettin. Influence of the circumglobal wave-train on European summer precipitation. Clim. Dyn., 43(1-2):503-515, 2014. doi: 10.1007/ s00382-013-1871-0.

I. R. Simpson and P. D. Jones. Updated precipitation series for the UK derived from Met Office gridded data. Int. J. Climatol., 32(15):2271-2282, 2012. doi: 10.1002/joc.3397.

R. T. Sutton and B. Dong. Atlantic Ocean influence on a shift in European climate in the 1990s. Nature Geoscience, 5(11):788-792, 2012. doi: 10.1038/ngeo1595. 
R. T. Sutton and D. L. R. Hodson. Atlantic Ocean forcing of North American and European summer climate. Science, 309(5731):115-118, 2005. doi: 10.1126/science.1109496.

$\mathrm{R}$ Thompson. A time-series analysis of the changing seasonality of precipitation in the British Isles and neighbouring areas. J. Hydrol., 224(3-4):169-183, 1999. doi: 10.1016/S0022-1694(99) 00129-8.

K. E. Trenberth, A. Dai, R. M. Rasmussen, and D. B. Parsons. The changing character of precipitation. Bull. Amer. Meteor. Soc., 84(9):1205-1218, 2003. doi: http://dx.doi.org/10.1175/ BAMS-84-9-1205.

J. Wibig. Precipitation in europe in relation to circulation patterns at the 500 hpa level. Int. J. Climatol., 19(3):253-269, 1999. doi: 10.1002/(SICI)1097-0088(19990315)19:3〈253::AID-JOC366〉3. $0 . \mathrm{CO} ; 2-0$.

T. M. L. Wigley and P. D. Jones. England and Wales precipitation: A discussion of recent changes in variability and an update to 1985. J. Climatol., 7(3):231-246, 1987. doi: 10.1002/ joc.3370070304.

T. M. L. Wigley, K. R. Briffa, and P. D. Jones. On the average value of correlated time series, with applications in dendroclimatology and hydrometeorology. J. Clim. Appl. Meteorol., 23:201-213, 1984a. doi: 10.1175/1520-0450(1984)023〈0201:OTAVOC $\rangle 2.0 . C O ; 2$.

T. M. L. Wigley, J. M. Lough, and P. D. Jones. Spatial patterns of precipitation in England and Wales and a revised, homogeneous England and Wales precipitation series. J. Climatol., 4(1): 1-25, 1984b. doi: 10.1002/joc.3370040102.

R L Wilby, P G Whitehead, A J Wade, D. Butterfield, R J Davis, and G. Watts. Integrated modelling of climate change impacts on water resources and quality in a lowland catchment: River Kennet, UK. J. Hydrol., 330(1):204-220, 2006. doi: 10.1016/j.jhydrol.2006.04.033.

N. L. H. Wood. Regional climate trends in south-west England and the North Atlantic Oscillation. Weather, 59(2):39-41, 2004. doi: 10.1256/wea.28.03.

M. R. Woodley. A review of two national rainfall series. Int. J. Climatol., 16(6):677-687, 1996. doi: 10.1002/(SICI)1097-0088(199606)16:6〈677::AID-JOC43〉3.0.CO;2-X. 
${ }_{568}$ T. Woollings, A. Hannachi, and B.J. Hoskins. Variability of the North Atlantic eddy-driven jet ${ }_{569}$ stream. Q. J. R. Meteorol. Soc., 136(649):856-868, 2010. doi: 10.1002/qj.625. 


\begin{tabular}{l||c|c||c|c|c|c|} 
& Total EWP & SD & $1931-2014$ & $1961-2006$ & $1961-2014$ & $1979-2014$ \\
\hline Annual & 931 & 115.1 & 0.85 & 1.35 & 1.82 & 1.32 \\
DJF & 255 & 70.0 & 0.43 & 0.48 & 0.81 & 0.36 \\
MAM & 191 & 51.1 & 0.18 & -0.07 & -0.28 & -1.22 \\
JJA & 216 & 61.1 & 0.05 & -0.33 & 0.59 & 1.63 \\
SON & 271 & 71.8 & 0.20 & 1.16 & 0.70 & 0.34 \\
\hline
\end{tabular}

Table 1: The annual and seasonal average EWP precipitation ( $\mathrm{mm})$, the standard deviation SD $(\mathrm{mm})$ as a measure of variability based on the period 1931-2014 (1932-2014 for DJF). In remaining columns show the precipitation trends (mm/year) based on a linear least squares fit for four relevant time windows (1931-2014, 1961-2006, 1961-2014 and the ERA-Interim period 1979-2014).

\begin{tabular}{l||c|c|c|c|} 
& 1 day & 3 days & 5 days & 10 days \\
\hline Annual & 13.8 & 28.0 & 40.9 & 69.3 \\
DJF & 13.8 & 28.2 & 42.1 & 71.1 \\
MAM & 12.0 & 23.5 & 33.0 & 54.3 \\
JJA & 13.5 & 26.3 & 37.6 & 62.9 \\
SON & 15.8 & 31.8 & 45.7 & 76.9 \\
\hline
\end{tabular}

Table 2: Threshold values $(\mathrm{mm})$ for extreme daily and multi-day accumulations for both annual and seasonal EWP observations. Extremes are defined by the upper $2 \%$ of the precipitation accumulations. 


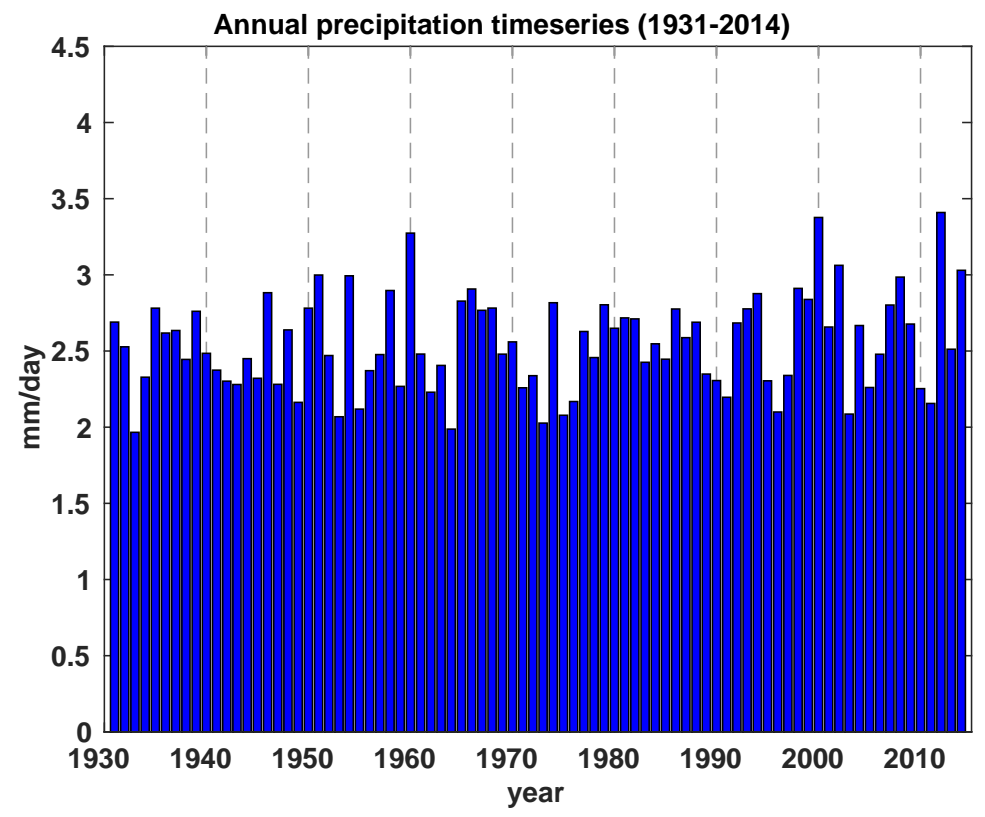

Figure 1: Timeseries of the annual precipitation accumulations between 1931-2014 (mm/day). 


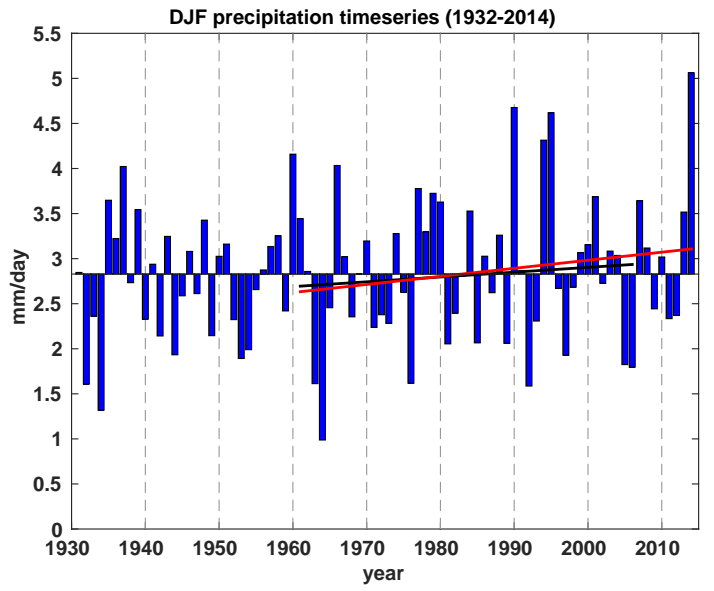

(a)

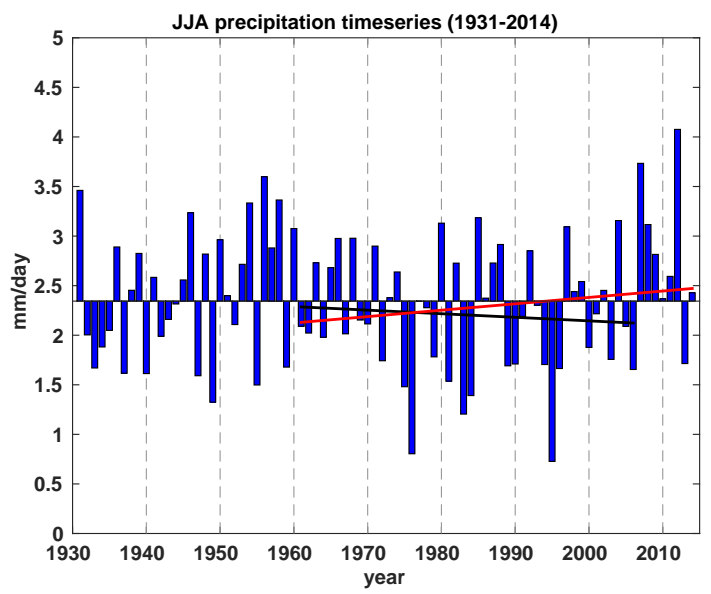

(c)

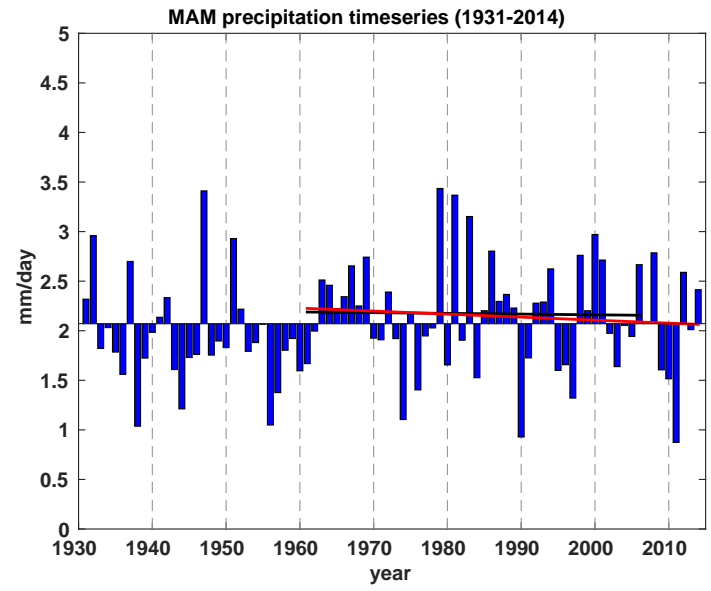

(b)

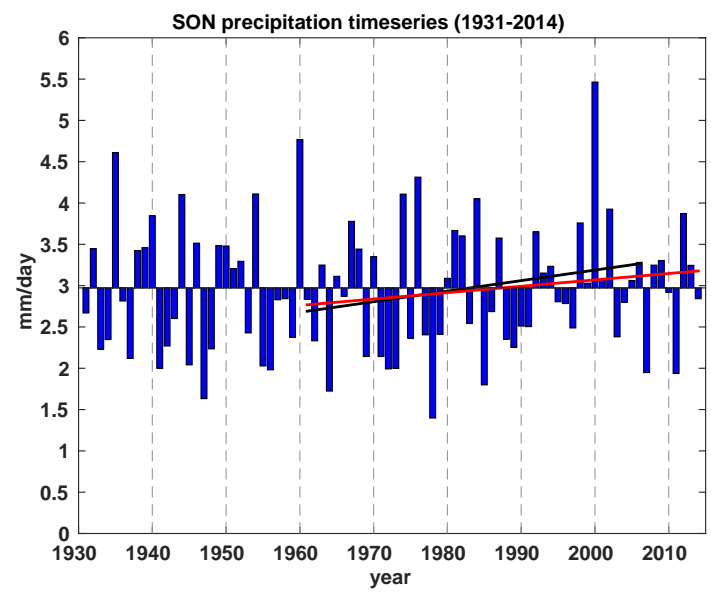

(d)

Figure 2: The anomalies compared to the mean daily precipitation between 1932-2014 for a) winter (DJF) and between 1931-2014 for b) spring (MAM), c) summer (JJA) and d) autumn (SON). Included are the identified trend (black line) for the time period 1961-2006 used in a previous study by Maraun et al. [2008] and the trend (red line) including the last 8 years (1961-2014). See table 1 for values. Note that the identified trends are not significant on the $95 \%$ significance level when using the entire dataset (1931-2014). 


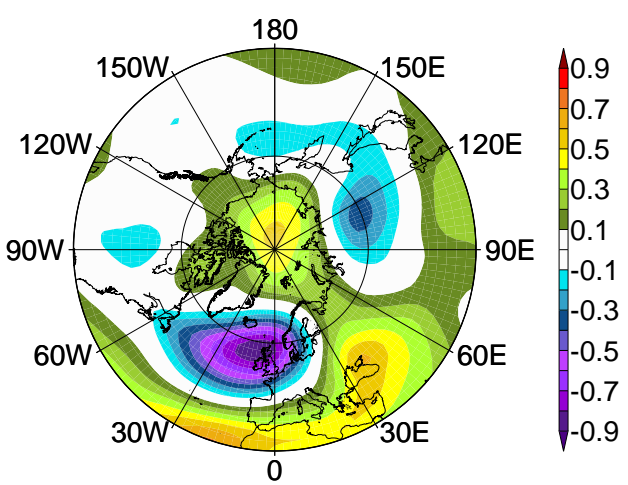

(a) DJF

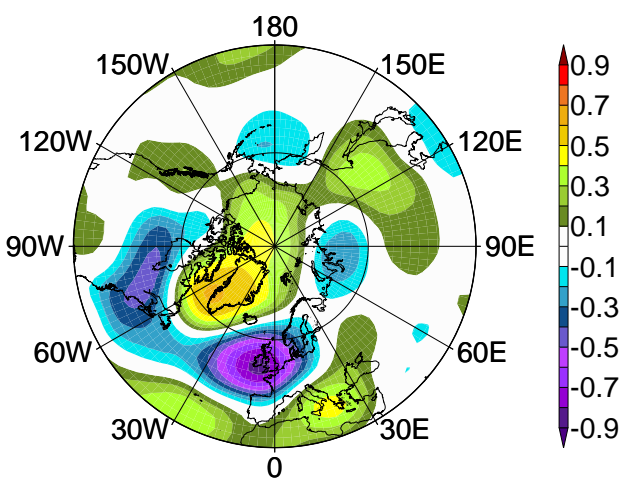

(c) JJA

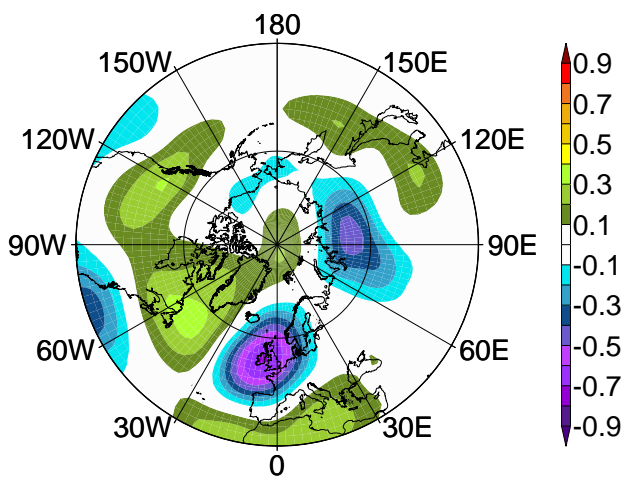

(b) MAM

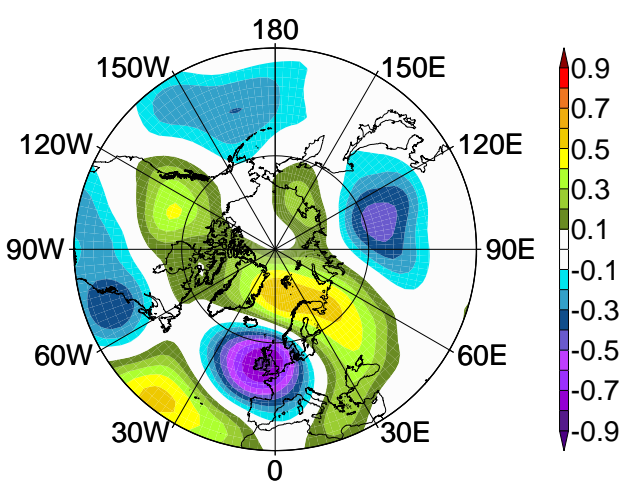

(d) SON

Figure 3: Pointwise, temporal correlation of the seasonal average 500hPa geopotential height from NCEP-NCAR reanalysis with EWP observations (1961-2013) for each of the four calendar seasons. 


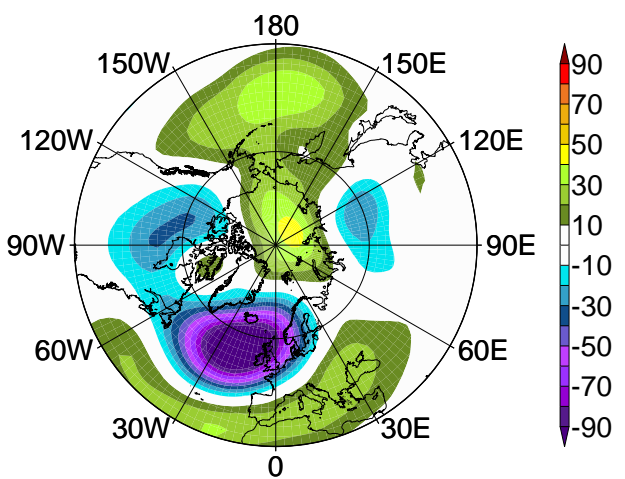

(a) DJF wet

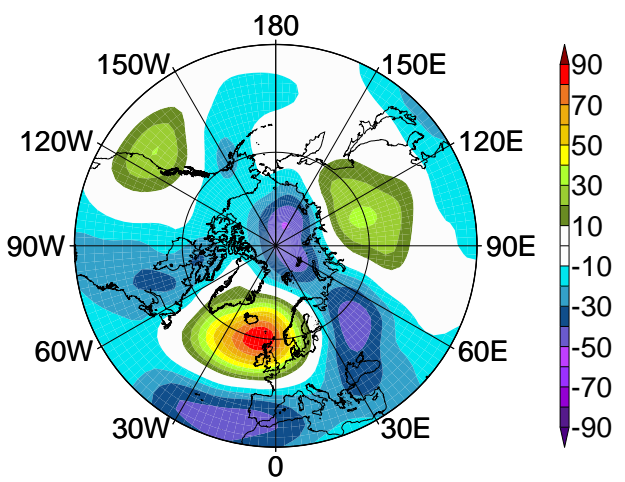

(c) DJF dry

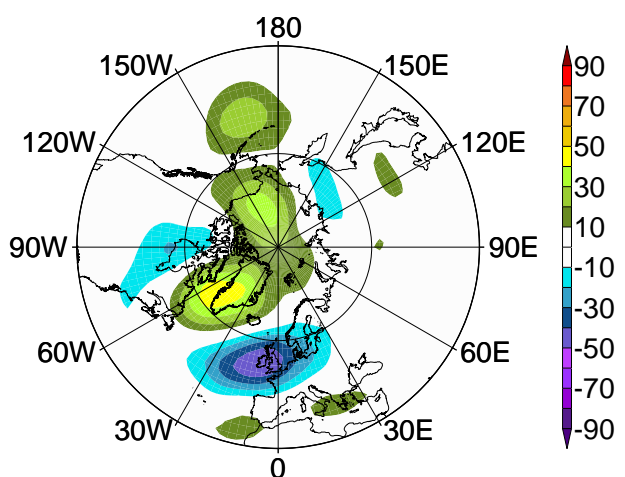

(b) JJA wet

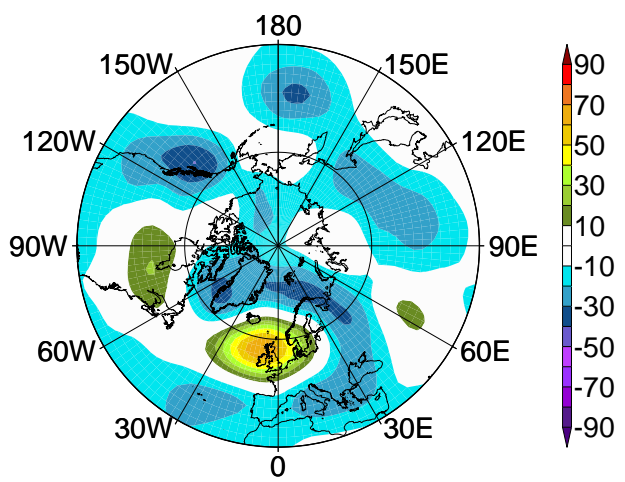

(d) JJA dry

Figure 4: The NCEP-NCAR reanalysis seasonal 500hPa geopotential height anomalies (m) for the composited of the five seasons between 1981-2013 based on EWP observations with a) the most precipitation in winter b) most precipitation in summer, c) least precipitation in winter and d) least precipitation in summer. 


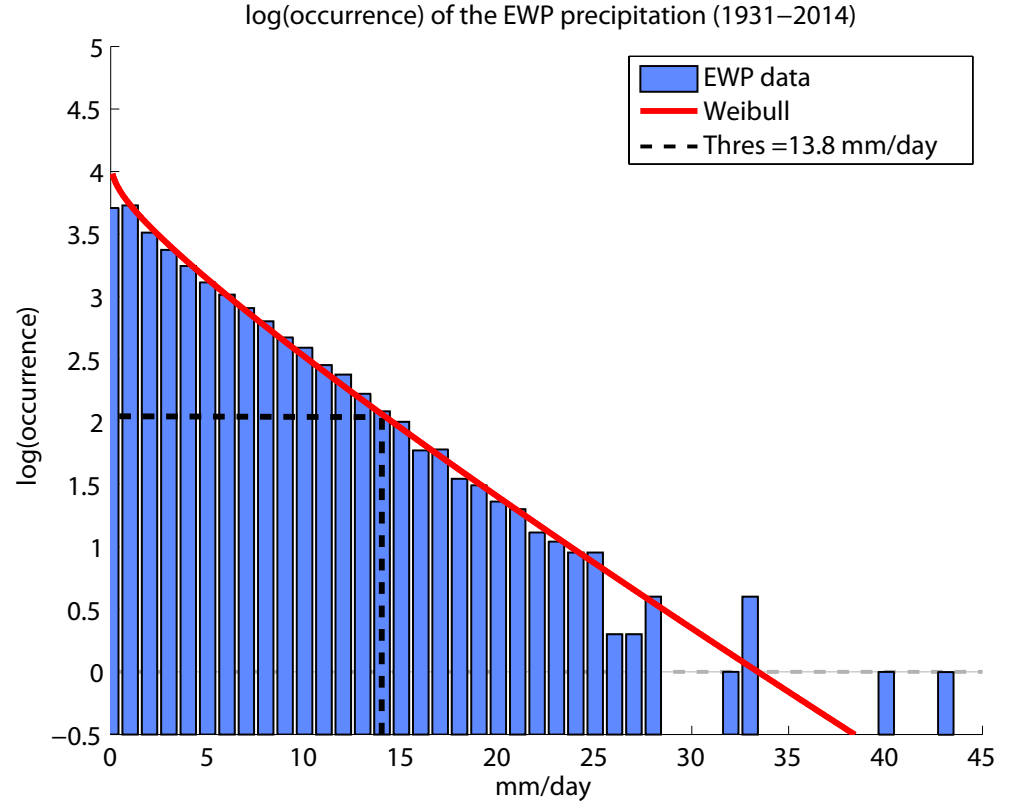

Figure 5: The frequency of daily precipitation as a function of precipitation intensity. The solid line indicates the best Weibull fit to the observations. The black dashed line indicates the $98 \%$ value used to define extreme events. 

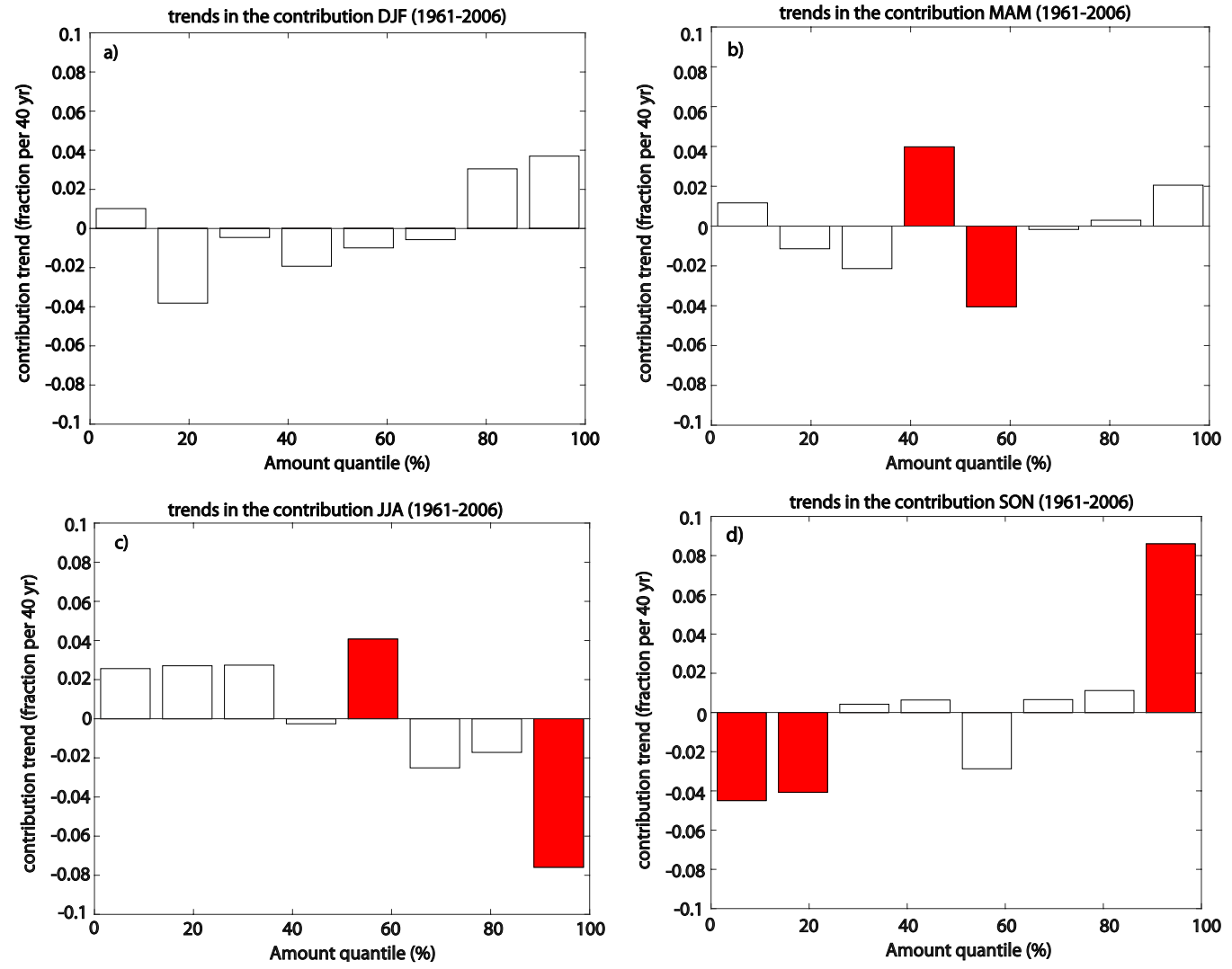

Figure 6: Trend over the years 1961-2006 for 8 EWP precipitation intensity categories, using the method and period described by Osborn et al. [2000] and Maraun et al. [2008]. The results are shown for a) winter (DJF), b) spring (MAM), c) summer (JJA) and autumn (SON). Coloured bars indicate trends that are significant at the $90 \%$ level using a standard Mann-Kendall trend test. The contribution trend as shown on the y-axis is the change in precipitation fraction over 40 years relative to the mean, where the mean fraction for each category is 0.125 . 

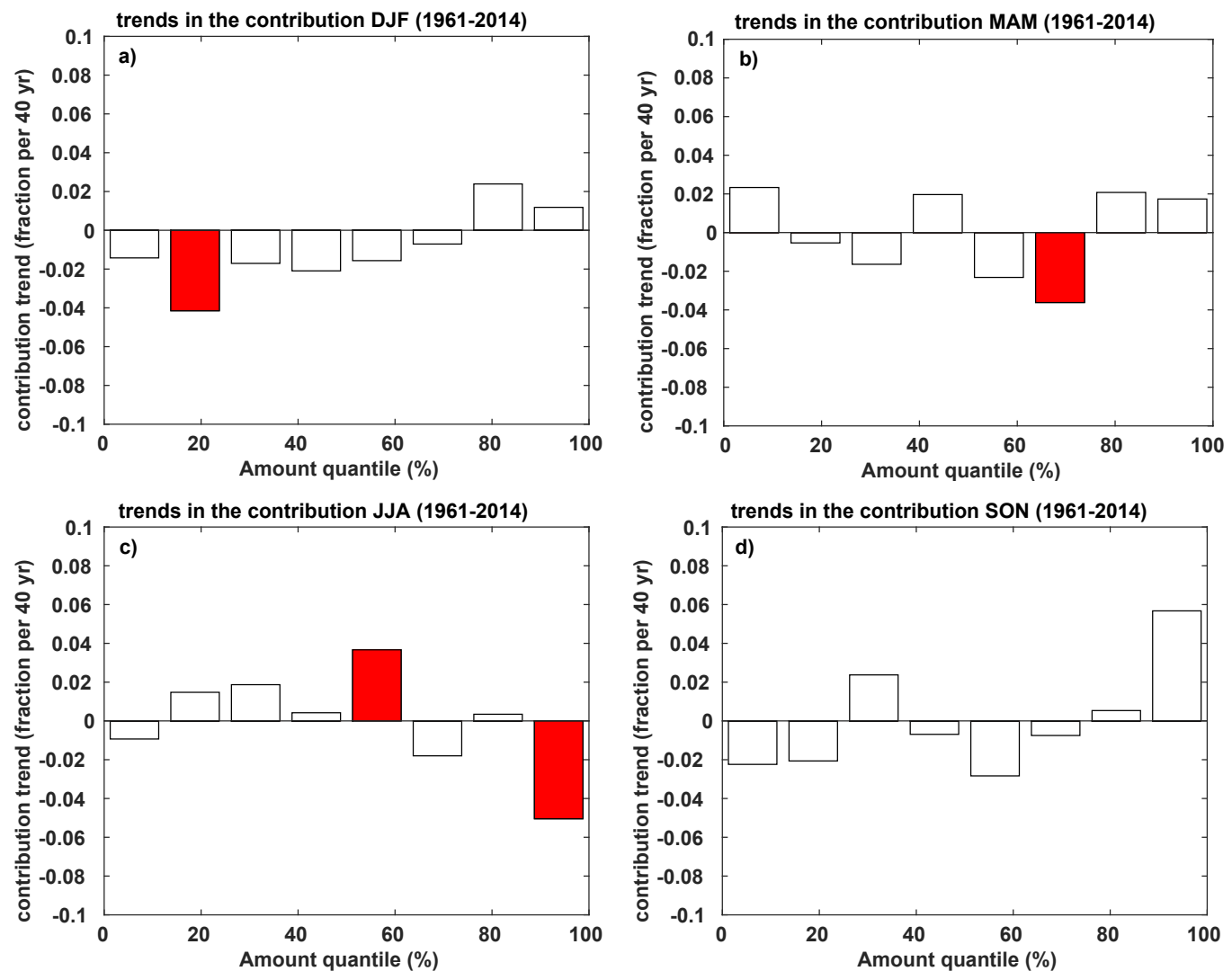

Figure 7: As for figure 6, but for the extended period 1961-2014. 


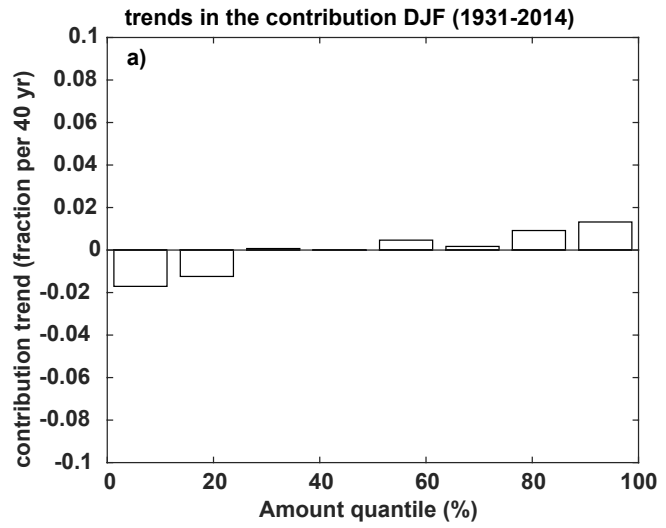

(a)

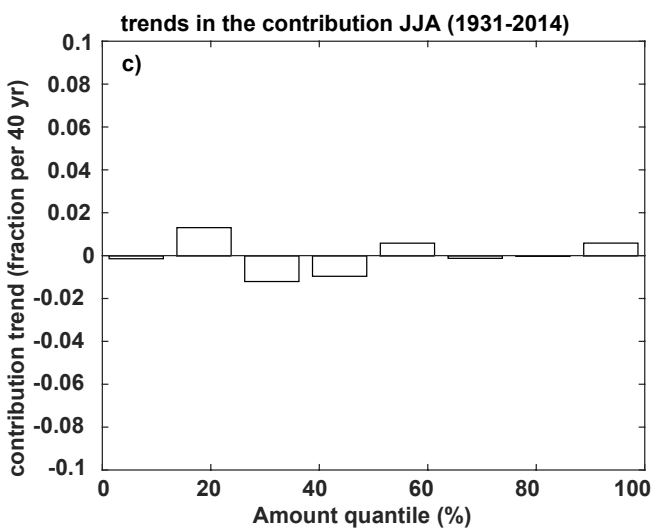

(c)

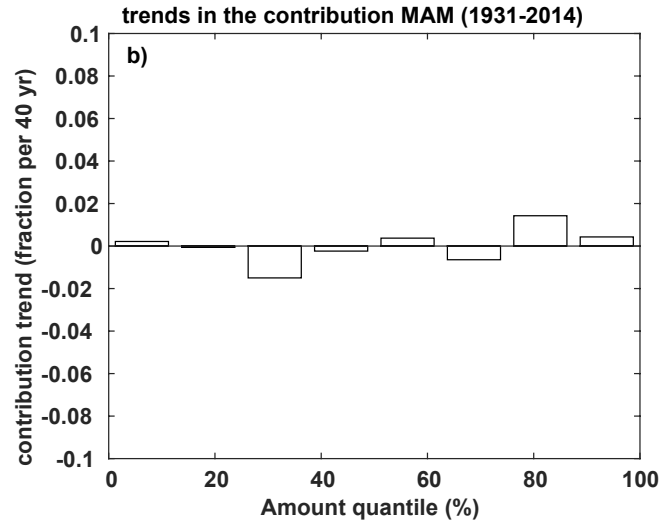

(b)

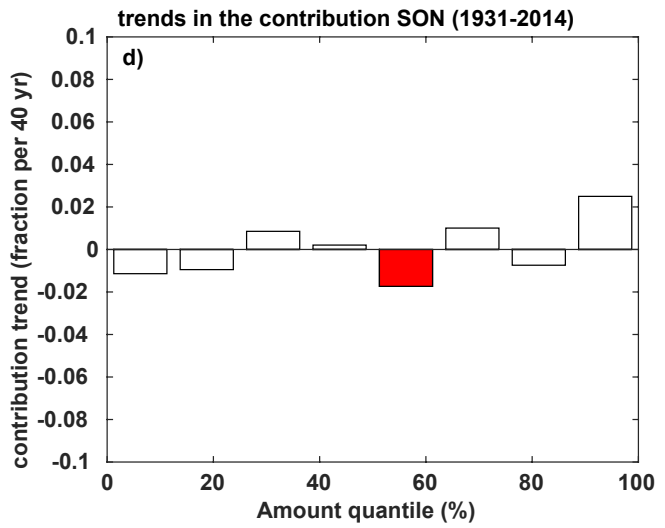

(d)

Figure 8: As for figure 6, but for the extended period 1931-2014. 


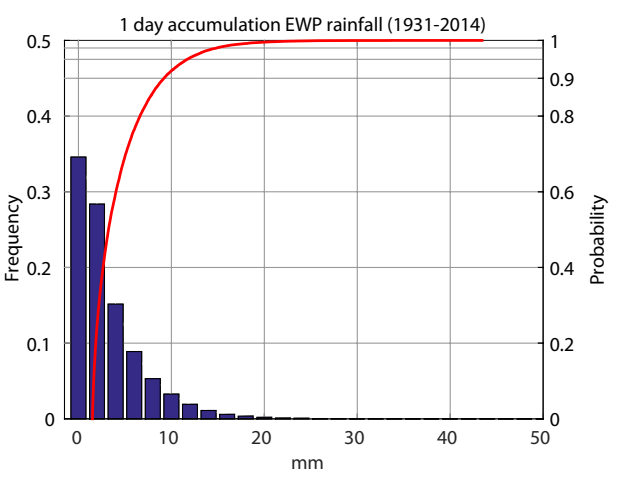

(a)

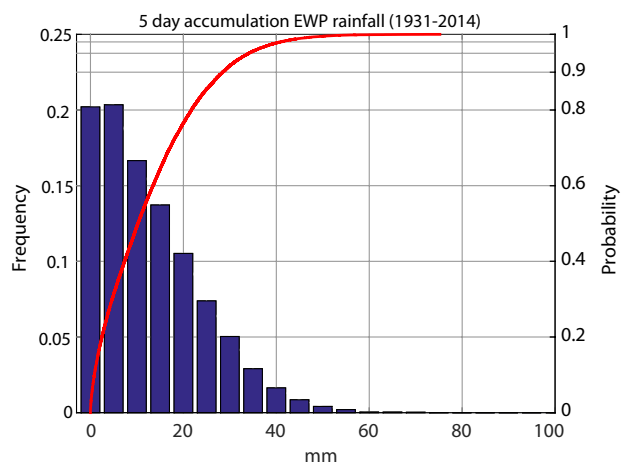

(c)

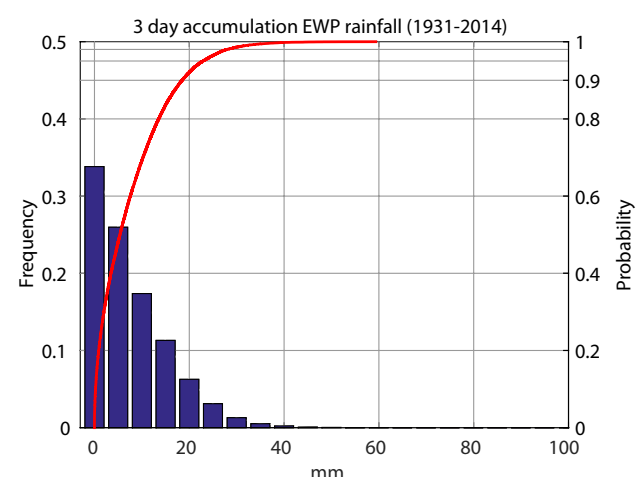

(b)

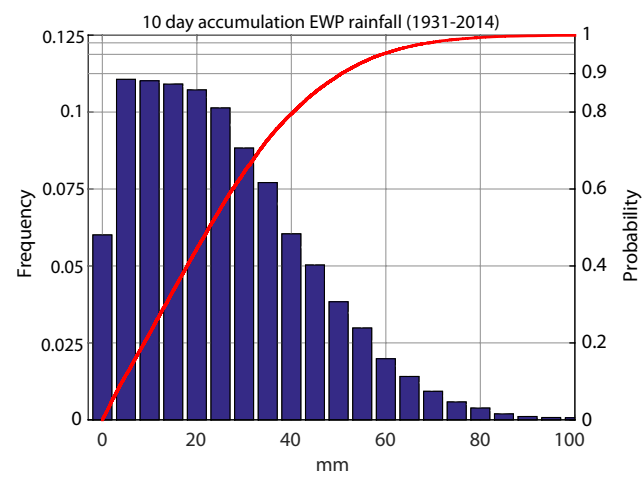

(d)

Figure 9: Normalised probability distribution functions (PDFs) of 1,3,5 and 10 precipitation accumulations (1931-2014). The corresponding cumulative distribution functions (CDFs) are shown by solid lines. The dashed grey lines indicate the specific quantiles as labeled on the right hand side axis in each panel. The top two lines indicate the $95 \%$ and $98 \%$ probability lines. The corresponding precipitation values for the $98 \%$ threshold are summarised in table 2 . 


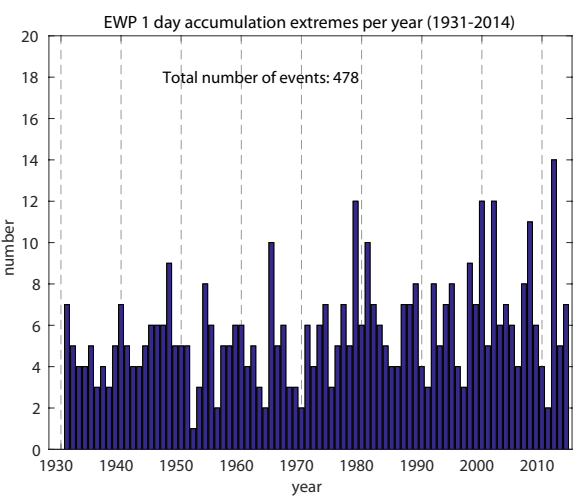

(a)

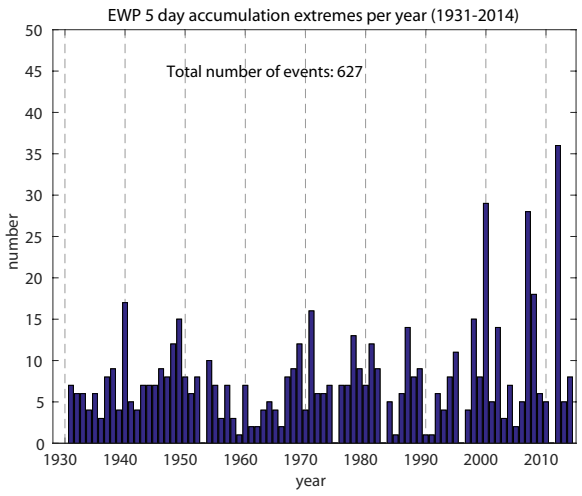

(c)

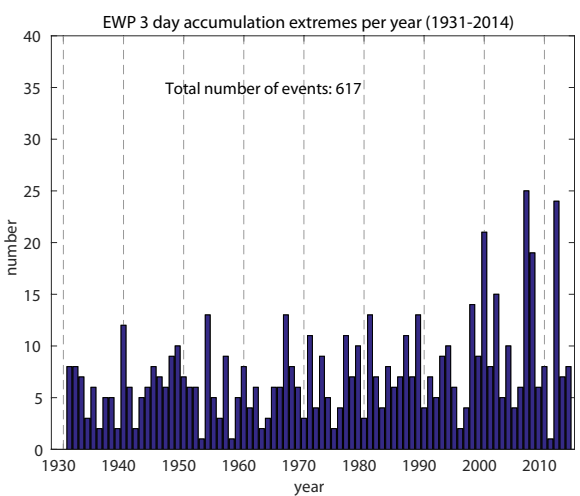

(b)

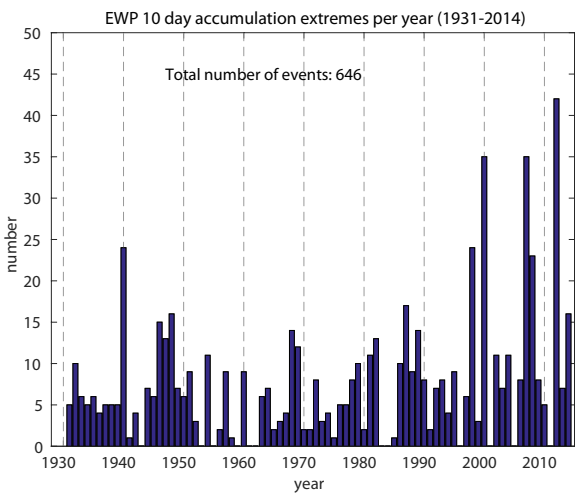

(d)

Figure 10: Counts of extreme days per calendar year (January 1931 - December 2014) measured by overlapping multi-day a) 1 day, b) 3-day, c) 5-day and d) 10-day precipitation accumulations. The extremes exceed the $98 \%$ threshold derived from all the data for each season separately (figure 9). The corresponding threshold precipitation values are given in table 2. 